\title{
Biogenic Amines and Collective Organization in a Superorganism: Neuromodulation of Social Behavior in Ants
}

\author{
J. Frances Kamhi ${ }^{a, b} \quad$ James F.A. Traniello ${ }^{a}$ \\ ${ }^{a}$ Department of Biology and ${ }^{b}$ Graduate Program for Neuroscience, Boston University, Boston, Mass., USA
}

\author{
Key Words \\ Aminergic regulation - Division of labor - Serotonin . \\ Dopamine - Octopamine $\cdot$ Neuromodulation . \\ Communication - Social brain - Collective intelligence
}

\begin{abstract}
The ecological dominance of ants has to a great extent been achieved through their collective action and complex social organization. Ants provide diverse model systems to examine the neural underpinnings of individual behavior and group action that contribute to their evolutionary success. Core elements of ant colony structure such as reproductive and ergonomic division of labor, task specialization, and social integration are beginning to be understood in terms of cellular neuroanatomy and neurochemistry. In this review we discuss the neuroethology of colony organization by focusing on the role of biogenic amines in the control of social behavior in ants. We examine the role of neuromodulation in significant sociobiological characteristics of ants, including reproductive hierarchies, colony foundation, social food flow, nestmate recognition, territoriality, and size- and agerelated sensory perception and task performance as well as the involvement of monoamines in collective intelligence, the ultimate key to the global dominance of these remarkable superorganisms. We conclude by suggesting future directions for the analysis of the aminergic regulation of behavior and social complexity in ants.

(c) 2013 S. Karger AG, Basel
\end{abstract}

\section{Introduction}

Invertebrates have long served as important models in neuroethology. The comparative simplicity of roundworm, mollusk, and arthropod neural architecture, wide range of behaviors, relative ease of culture, and experimental utility have revealed molecular and cellular underpinnings of sensory and motor processes that improve the survival and fitness of individual animals. Ants, as social invertebrates, provide novel opportunities to neuroethologically examine the genesis of complex social behavior from a miniscule brain composed of a small number of neurons and relatively simple circuitry [Gronenberg, 1996]. Ants are ubiquitous models of biological complexity renowned for their highly organized colonies and ability to exceed individual behavioral capacities by integrating activities of single workers into group behaviors, thus acting as a superorganism. For example, leafcutter ants, one paradigm of social complexity in this clade, maintain an agricultural system with a mutualistic fungus and sustain colonies of more than a million individuals. Individual ants make local contributions to colony labor: workers cut or transport leaves, implant fungal hyphae, fertilize the fungal comb with fresh mulch, maintain sanitation to control infection, and provide colony security [Wilson, 1980]. The summed actions of colony members result in an extraordinarily well-organized farming community without centralized supervision.

\section{KARGER}

E-Mail karger@karger.com

www.karger.com/bbe (c) 2013 S. Karger AG, Basel

0006-8977/13/0824-0220\$38.00/0
J. Frances Kamhi

Biology Department

Boston University

Boston, MA 02215 (USA)

E-Mail jfkamhi@bu.edu 
Ants can provide insight into the neurobiological mechanisms of such sophisticated cooperative and collective action and are emerging as powerful models to explore the neuroanatomy and neurochemistry of development, plasticity, evolution, and ecology of behavioral differentiation and sociality. Given their remarkable species richness ( $>12,500$ identified species) and dominance in abundance and biomass, ants present diverse opportunities to elucidate the neural underpinnings of adaptive individual and group-level actions in an animal long reputed for its relatively simple neural architecture but extraordinary behavioral capability. Ant brains can be smaller than 1/100th of the volume of a honeybee brain, which itself is minute $\left[0.64 \pm 0.12 \mathrm{~mm}^{3}\right.$; Mares et al., 2005]. The genesis of adaptive behavior from such a miniscule amount of nervous tissue has long captivated researchers. Darwin [1871] considered the ant brain to be 'one of the most marvelous atoms of matter in the world, perhaps more so than the brain of a man'. Ant brains reflect evolutionary responses to social selection, and they possess 'social brains' in the same sense that nervous systems in all group-living animals reflect cognitive adaptations to the challenges of social life [Dunbar and Shultz, 2007]. Methods enabling analyses of the cellular and macroscopic neuroanatomy and neurochemistry of ant brains are well developed [Groh and Rössler, 2011; Muscedere et al., 2012, 2013; Muscedere and Traniello, 2012]. There is currently unprecedented interest in brain miniaturization and its relation to sociality [Wehner et al., 2007; Chittka and Niven, 2009; Seid et al., 2011; Eberhard and Wcislo, 2012; Niven and Farris, 2012]. There are also compelling studies on the influence of monoamines on social behavior; for example, swarm formation has been causally linked to the release of neurochemicals in desert locusts [Anstey et al., 2009]. Monoamines may play a significant role in processing stimuli to enable monitoring of the social environment and perhaps serve important functions in the control of behavior and colony organization in social insects such as ants, bees, and wasps (order Hymenoptera) and termites (order Isoptera) [Giurfa, 2006; Neckameyer and Leal, 2009; Tedjakumala and Giurfa, 2013].

The orchestration hypothesis [Hoyle, 1985] notes that neurochemical release stimulates specific neural circuits underlying behavior and makes testable predictions about the coordination of social behavior by monoamines. Research on invertebrate neurochemical circuitry [Kravitz and Huber, 2003; Libersat and Pflueger, 2004; Neckameyer and Leal, 2009; Riffell et al., 2013] includes studies of the regulation of flight [Orchard et al., 1993],

Neuromodulation of Social Behavior in Ants grooming [Weisel-Eichler et al., 1999], hygienic behavior [Spivak et al., 2003], mate attraction [Christensen et al., 1992], aggression [Huber et al., 1997; Baier et al., 2002; Huber, 2005], and learning [Tedjakumala and Giurfa, 2013] in crickets, honeybees, locusts, roaches, and crustaceans. In honeybees, workers show chronological and physiological age-related variation in brain structure and monoamine levels, which adjust colony labor profiles in relation to colony needs and behavioral development [Schulz and Robinson, 2001; Schulz et al., 2002, 2003; Barron and Robinson, 2005]. Comparable research has only recently begun in ants; however, there is evidence supporting the hypothesis that social organization is based on neurally differentiated worker phenotypes [Wnuk et al., 2010; Muscedere and Traniello, 2012] whose patterns of task performance are dependent on aminergically controlled sensitivity to social signals [Vander Meer et al., 2008; Muscedere et al., 2012].

The confluence of interests in insect social brain evolution, brain miniaturization, and mechanistic research in the neuromodulation of behavior offers the possibility of novel explorations of worker task capability, colony-level performance, neuroarchitecture, and neurochemistry in ants to advance our understanding of the underpinnings of complex social behavior. This is the emphasis of our review. We develop an integrative sociobiological and neuroethological framework to examine the role of the biogenic amines serotonin (5-HT), dopamine (DA), and octopamine (OA) in the modulation of social behavior, colony-level division of labor in ants, and collective intelligence. We conclude with a prospectus for future studies on the aminergic regulation of ant behavior.

\section{The Organization of Ant Colonies: Sensory Environments of Worker Behavior}

All ants, representing a single hymenopteran family, the Formicidae, are eusocial. Colony social phenotype is universally defined by 3 traits: reproductive specialization (the coexistence of a fertile queen and sterile worker offspring; fig. 1), allomaternal care (shared nursing of immature offspring by adult workers), and overlapping generations (queen longevity sufficient for coexistence with her offspring). Mating behaviors are thus absent from worker repertoires, and queens do not contribute to colony labor. In a typical colony life cycle, winged gynes (virgin queens) disperse from their parent colony and outbreed with winged males, which die soon after mating. Newly inseminated queens shed their wings, construct a 


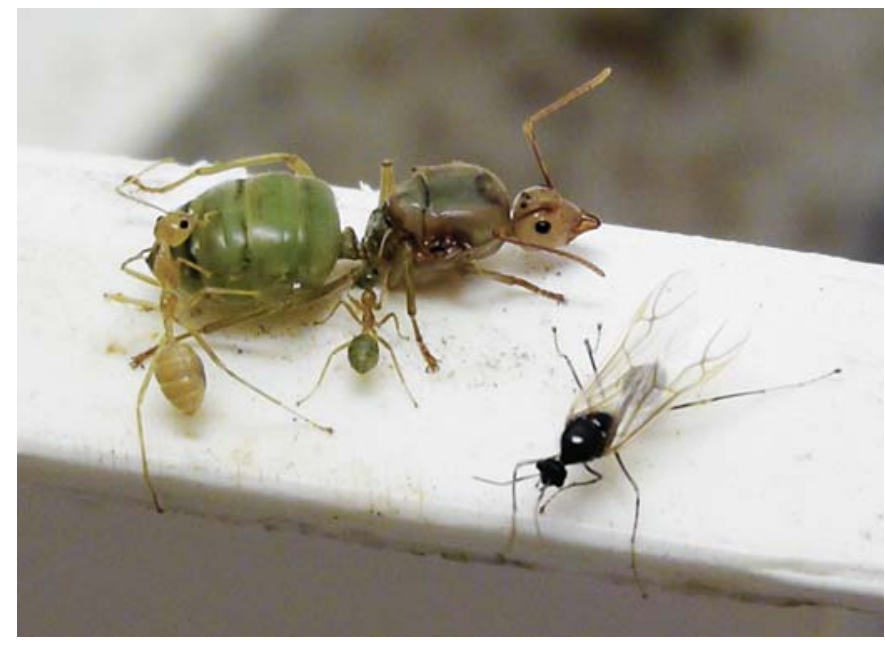

Fig. 1. Reproductive caste and worker subcastes of the Australian weaver ant O. smaragdina. Clockwise from the top: queen, winged male, mature minor worker, newly eclosed major worker. Not illustrated: winged gyne (virgin female). Photo courtesy of J. Evans.

nest, and rear their first worker brood using energy gained from metabolizing their wing muscles [Hölldobler and Wilson, 1990]. After the maturation of the first brood, queens become wholly specialized in reproduction and workers perform nursing, foraging, nest maintenance, and defense tasks. Workers recognize nestmates and aggressively discriminate against individuals from other colonies encountered while patrolling their territory or intruding in the nest. The biology of reproductive and sterile castes and the themes of cooperation, altruism, intense social interaction, and elaborate social networks are core elements of ant sociobiology.

Division of labor among workers is the basis of ergonomic organization in ant colonies. Through worker task specializations, division of labor enhances efficiency and thus the productivity and reproductive success of the colony [Hölldobler and Wilson, 1990, 2009]. Worker social roles can be correlated with morphological variability, at times leading to the evolution of size-differentiated subcastes. For example, relatively large-bodied workers, 'soldiers', or majors, are typically aggressive and involved in nest defense and territory security, whereas smaller workers (e.g. minors) nurse brood, maintain the nest, manage infectious waste, and forage [Seid and Traniello, 2006] (fig. 2). Task performance may also be coupled to age [reviewed in Seid and Traniello, 2006] and genetic architecture [Snyder, 1992; Libbrecht et al., 2011; Schluns et al., 2011]. Worker behavior is not fixed according to size, age, or task load and can be modified to allow flexible responses to colony needs [Seid and Traniello, 2006; Muscedere et al., 2009; Gordon, 2010]. Worker attendance to a given task or task set may depend upon thresholds of responsiveness to cues in the environment and interactions with nestmates [Robinson, 1992; Beshers and Fewell, 2001; Gordon, 2010]. Patterns of task attendance may be narrow, as in the case of specialist workers in a polymorphic species that may only process or store food, or broad, as is true for species characterized by monomorphic caste distributions and generalist workers [Hölldobler and Wilson, 1990].

Division of labor reflects energetic needs first associated with somatic growth and then the reproductive phases of the colony life cycle. Eggs produced by the queen develop into nutritionally dependent larvae that increase in size from worker provisioning, molt through a number of instars, and subsequently pupate. Each developmental stage likely has a chemical signature identifying colony identity and perhaps instar and nutritional state [Brian, 1975; den Boer and Duchateau, 2006; Cotoneschi et al., 2007]. Immatures must be maintained in temperature and humidity regimes favorable to the requirements for development of each stage, and eggs, larvae, and pupae are transported accordingly among nest chambers [Anderson and Munger, 2003]. The information content of larval or pupal chemical cues and signals induces behavioral responses dependent on worker developmental stage, social role, experience, and colony need [Hölldobler and Wilson, 1990; Gordon, 2010]. Beginning with adult eclosion, workers respond to their physical and social world by processing information encoded in olfactory, tactile, seismic, and visual signals and sensing chemical, thermal, and hygrometric clines [Billen and Morgan, 1998; Roces and Kleineidam, 2000; Kleineidam et al., 2007]. Processing sensory input is thus critical to social behavior.

The first environment of task performance of a newly eclosed adult worker ant is the dark, labyrinthal interior of a nest, typically in a log or soil nest, perhaps deep beneath the surface. At this early stage of adulthood, it is likely that most workers interact through chemical communication with their nestmates in only a few basic ways and have the physical ability to attend to only the least demanding of tasks. Newly eclosed workers, or callows, are typically light in color due to incomplete cuticular sclerotization. The unhardened integument renders them vulnerable to attack, and muscle groups supporting the movement of the mandibles - the tools needed to work productively - are poorly developed [Muscedere et al., 2011]. Callows have a relatively low level of movement 
Fig. 2. Polymorphism in worker castes. a $P$. dentata minor and major workers $(\times 40)$. A. cephalotes workers: minim workers on a fungal comb (b), a media cutting a leaf (c), and a minim and a soldier (d). Scale bars $=1 \mathrm{~mm}$. A. cephalotes photos used with permission from ${ }^{\circledR}$ Alex Wild.
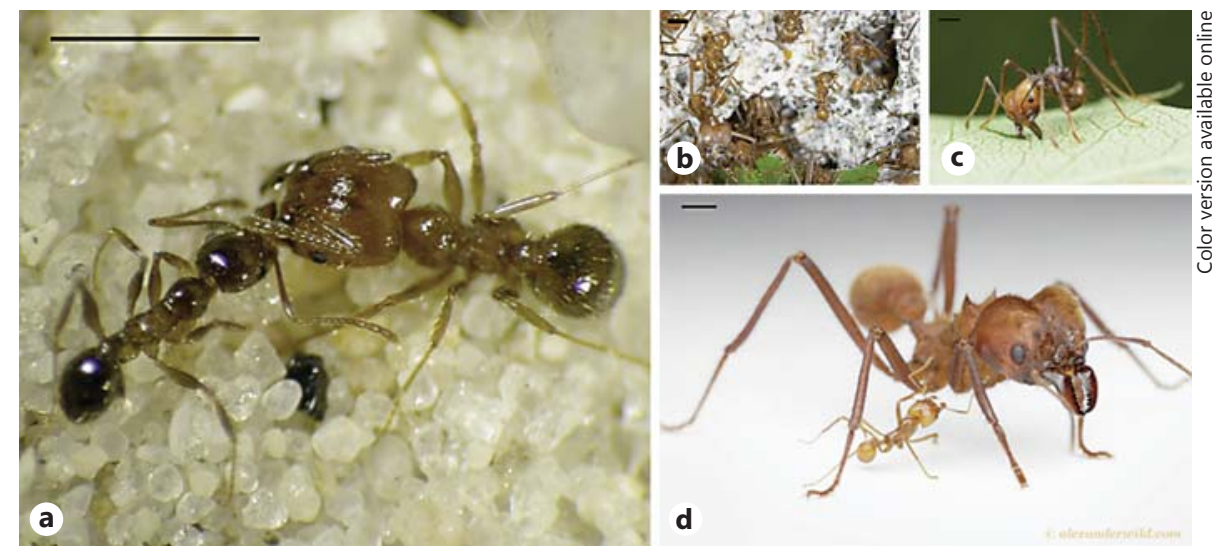

and task activity. With increasing sclerotization of the exoskeleton and neural and myological maturation, workers develop efficiency in their task performance [Muscedere et al., 2009]. As age increases, the sensory environment changes and workers are capable of more extensive locomotion. Behavioral development is typically marked by the onset of positive phototaxis, departure from the nest, and participation in food collection and territorial defense. These extranidal tasks involve the genesis of search patterns, pedometry, navigation, pheromone trail following, food recognition, food retrieval, predatory aggression, enemy identification, and interpretation of additional social signals. Worker size- and agerelated patterns of task performance and specialization are presumably underscored by neural characteristics that enable sensory processing and integration [Libersat and Pflueger, 2004; Seid and Traniello, 2005; Wnuk et al., 2010; Giraldo et al., 2013]. Ants are renowned for their cooperation and advanced sociality, but the neurobiological processes that give rise to their individual actions and colony organization are poorly understood.

\section{The Ant Nervous System}

\section{Brain Anatomy}

Hymenopteran brains exhibit a mosaic of functionally distinct compartments [Gronenberg, 2008] (fig. 3a, b). Sensory regions are the optic lobes, comprised of the lamina (which attaches to ommatidia), the medulla and lobula, and the antennal lobes, made up of glomeruli that have distinct spatial patterns of activation to encode specific odors [Zube et al., 2008; Brandstaetter and Kleineidam, 2011]. Mushroom body neuropil is dedicated to sensory integration, learning, and memory; typically, the calyx receives sensory input and the peduncle contains axons that project to various other brain regions [Fahrbach, 2006]. Chemical and visual inputs are segregated in the mushroom body calyx: the lip receives olfactory input from the antennal lobes, axons from the optic lobes innervate the collar, and the basal ring receives information from both primary sensory regions [Gronenberg, 2001]. The central body and protocerebral lobes complete the supraesophageal brain. The subesophageal ganglion is fused ventrally, and the ventral nerve cord, which extends throughout the body and controls movement, is comprised of 3 thoracic and a varying number of abdominal ganglia [Niven et al., 2008].

Three features distinguish ant brains from those of other hymenopterans: smaller optic lobes (with prominent exceptions in the highly visual ants Myrmecia, Gigantiops, and Cataglyphis), larger and more complex antennal lobes, and large mushroom bodies [Gronenberg, 1996]. These neural characteristics reflect the chemical basis of social life in ants, particularly in phylogenetically derived species. Most ant species rely heavily on pheromones to communicate in multiple contexts, identify nestmates and interact socially, mark territory, and orient.

\section{Neuromodulation}

The modulation of behavior by the biogenic amines 5-HT, DA, and OA depends on the nature of the G-protein-coupled receptors to which they bind. Each monoamine may have several associated receptor types acting through a different molecular mechanism. Little is understood about monoamine receptors in ants; however, immunolabeling monoamines has revealed distinct expression patterns in some species. In the ponerine ant Harpegnathos saltator, DA fibers innervate all regions of the mushroom bodies and densely innervate the central 

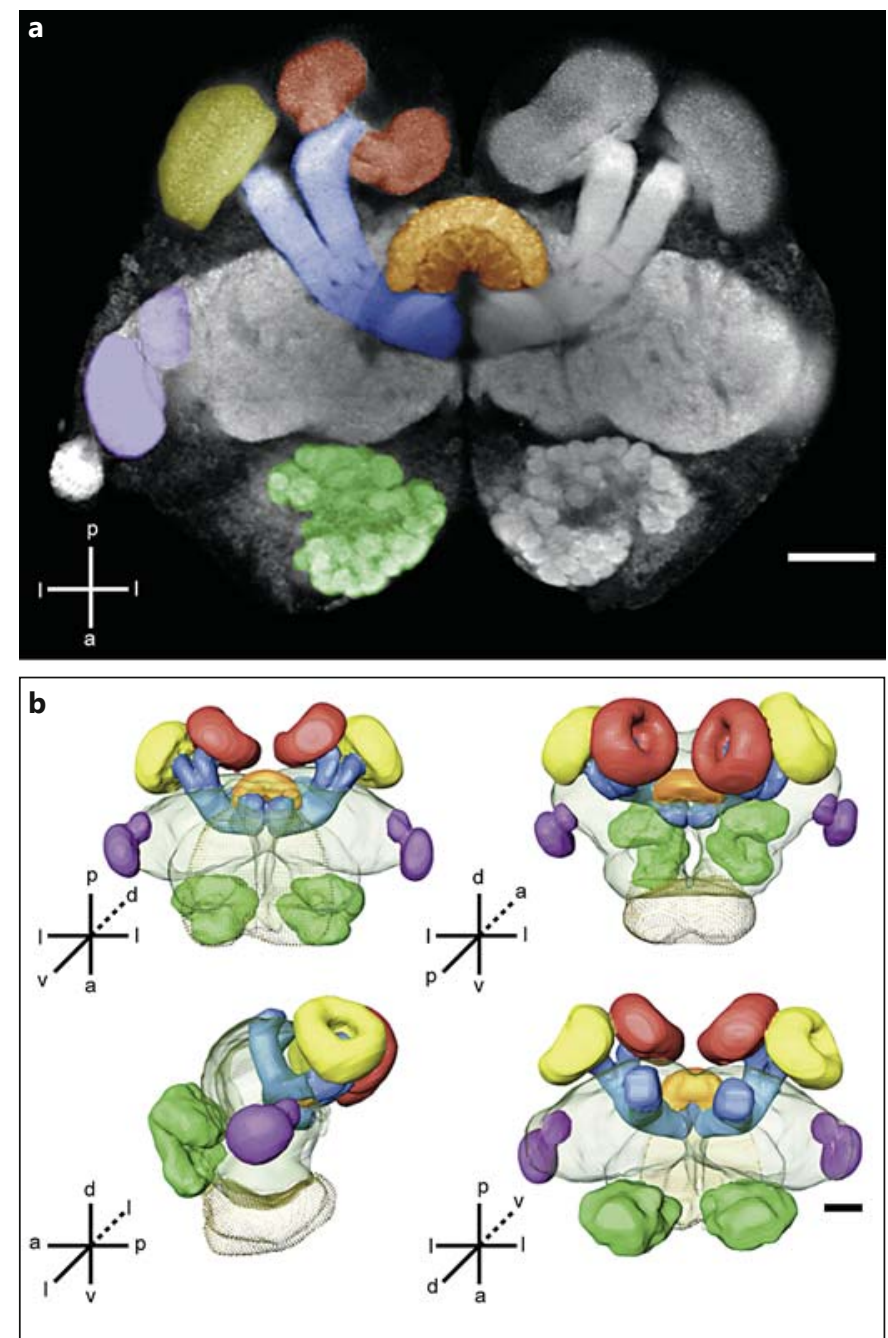

Fig. 3. Ant brain structure. Confocal image (a) and 3-D reconstructions (b) of the brain of a $P$. dentata mature major worker stained with anti-synapsin. Brain regions are false colored. Optic lobe (purple), antennal lobe (green), mushroom body mid calyx (red), lateral calyx (yellow), peduncle (blue), and central body (orange) (colors refer to the online version only). The subesophageal ganglion is not pictured. Scale bars $=50 \mu \mathrm{m}$. Image reprinted with permission from Muscedere and Traniello [2012].

body, but not the optic or antennal lobes [Hoyer et al., 2005] (fig. 4). In Pheidole dentata, newly eclosed and mature minor workers have similar dopaminergic innervation, suggesting these circuits are conserved during development and across ant species [Ibarraran and Abouheif, pers. commun.]. DA therefore may have a limited role in behavioral development and related changes in sensory processing.

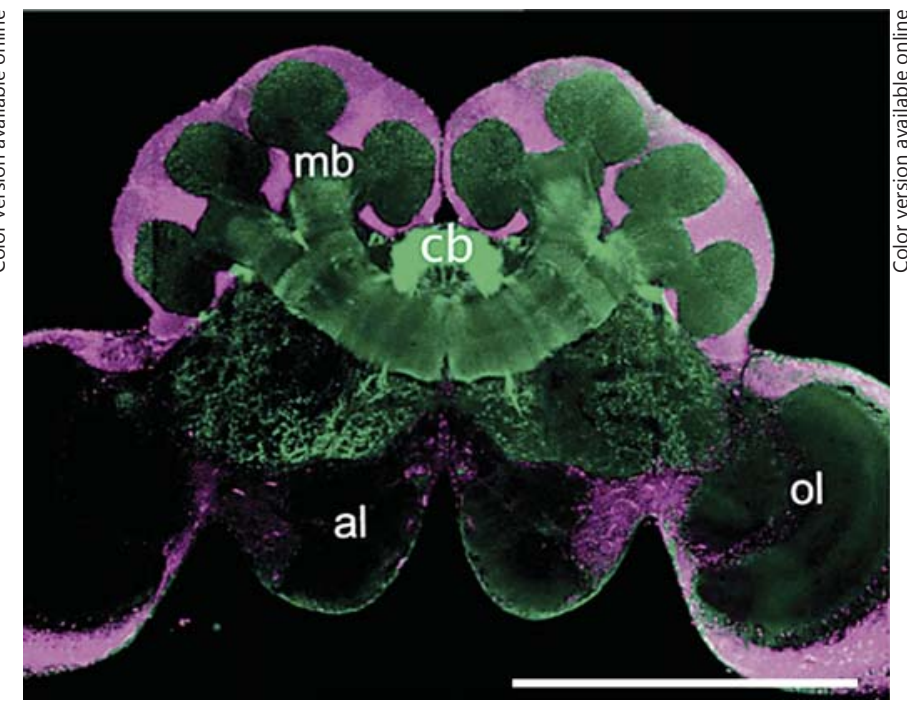

Fig. 4. H. saltator worker brain illustrating dopaminergic immunoreactivity (green) and prodium iodide-labeled nuclei (red) (colors refer to the online version only). Dopaminergic fibers project throughout the mushroom bodies (mb), heavily label the central body (cb), but do not innervate the optic (ol) and antennal lobes (al). Scale bar $=500 \mu \mathrm{m}$. Image reprinted with permission from Hoyer et al. [2005].

5-HT immunoreactive cell bodies have been identified in major and minor workers in the protocerebrum, subesophageal ganglion, and optic lobes, with diffuse innervation of all primary neuropil [Seid et al., 2008]. The number of serotonergic cell bodies increases significantly with age in the optic lobes of workers in both subcastes, implicating $5-\mathrm{HT}$ in the development of the visual system [Seid et al., 2008]. Similarly, the extrinsic serotonergic mushroom body calyx input neuron (CIN) has more elaborate axonal arborization in mature majors than in newly eclosed majors although there was no variation in age-related arborization in either subcaste when brain volume differences were controlled [Giraldo et al., 2013]. Subcaste distinctions also occur in the CIN: more elaborate axonal arborization was found in majors than in minors. These findings, along with those of neuropharmacological studies [Muscedere et al., 2012], suggest that 5-HT is associated with age- and subcaste-related task specializations, possibly by regulating olfactory sensitivity. $H$. saltator worker brains exhibit similar 5-HT expression [Hoyer et al., 2005]: serotonergic neurons innervate most of the prominent neuropil, with dense labeling of the central body and mushroom body penduncle and calyx lip. These studies relate age, subcaste, and 5-HT expression patterns, suggesting that worker behavior is under aminergic regulation (table 1). 
Table 1. Monoamines and social behavior in ants

\begin{tabular}{|c|c|c|c|}
\hline Behavior & $\mathrm{OA}$ & $\mathrm{DA}$ & 5-HT \\
\hline $\begin{array}{l}\text { Subcaste-related } \\
\text { division of labor }\end{array}$ & $\begin{array}{l}\text { A. echinatior [Smith et al., } \\
2013]^{\mathrm{a}}\end{array}$ & $\begin{array}{l}\text { P. dentata [Giraldo and } \\
\text { Traniello, unpubl. obs. }]^{\text {a. }} ; A . \\
\text { echinatior [Smith et al., 2013 }]^{\text {a }}\end{array}$ & $\begin{array}{l}\text { P. dentata [Giraldo et al., 2013; Giraldo } \\
\text { and Traniello, unpubl. obs. }{ }^{\text {a.; }} \text {; } \\
\text { echinatior [Smith et al., 2013] }\end{array}$ \\
\hline $\begin{array}{l}\text { Worker behavioral } \\
\text { development, } \\
\text { repertoire expansion, } \\
\text { and temporal } \\
\text { polyethism }\end{array}$ & $\begin{array}{l}\text { P. dentata [Seid and } \\
\text { Traniello, 2005]; S. peetersi } \\
\text { [Cuvillier-Hot and Lenoir, } \\
\text { 2006]; F. polyctena [Wnuk et } \\
\text { al., 2010] }\end{array}$ & $\begin{array}{l}\text { P. dentata [Seid and Traniello, } \\
\text { 2005] }]^{\text {a }} \text { S. peetersi }[\text { Cuvillier-Hot } \\
\text { and Lenoir, 2006] }]^{\text {a }} \text { F. polyctena } \\
\text { [Wnuk et al., 2010] }]^{\text {a }}\end{array}$ & $\begin{array}{l}\text { P. dentata [Seid and Traniello, 2005; } \\
\text { Seid et al., 2008; Muscedere et al., 2012; } \\
\text { Giraldo et al., 2013] }{ }^{\text {a }} \text {; } \\
\text { S. peetersi [Cuvillier-Hot and Lenoir, } \\
\text { 2006]; F. polyctena [Wnuk et al., 2010] }\end{array}$ \\
\hline $\begin{array}{l}\text { Predatory } \\
\text { aggression }\end{array}$ & $\begin{array}{l}\text { F. japonica }[\text { Aonuma and } \\
\text { Watanabe, } 2012 \mathrm{~b}]^{\mathrm{a}}\end{array}$ & $\begin{array}{l}\text { F. japonica [Aonuma and } \\
\text { Watanabe, } 2012 \mathrm{~b}]^{\mathrm{a}}\end{array}$ & $\begin{array}{l}\text { F. japonica [Aonuma and Watanabe, } \\
2012 \mathrm{~b}]^{\mathrm{a}} ; \text { P. dentata [Giraldo et al., } \\
\text { unpubl. obs.] }\end{array}$ \\
\hline $\begin{array}{l}\text { Nestmate } \\
\text { recognition }\end{array}$ & $\begin{array}{l}\text { C. fellah [Boulay et al., 2000] } \\
\text { S. invicta [Vander Meer et al., } \\
2008]^{\mathrm{a}} \text {; F. japonica } \\
\text { [Wada-Katsumata et al., 2011] } \\
\text { O. smaragdina [Kamhi and } \\
\text { Traniello, unpubl. obs.] }\end{array}$ & $\begin{array}{l}\text { S. invicta [Vander Meer et al., } \\
\text { 2008]; F. japonica } \\
\text { [Wada-Katsumata et al., 2011]; } \\
\text { O. smaragdina [Kamhi and } \\
\text { Traniello, unpubl. obs.] }\end{array}$ & $\begin{array}{l}\text { C. fellah [Boulay et al., 2000]; } \\
\text { O. smaragdina [Kamhi and Traniello, } \\
\text { unpubl. obs.] }\end{array}$ \\
\hline
\end{tabular}

Ant species and references are presented for specific social behaviors and the corresponding monoamines involved.

a Studies that demonstrate an association between amine level and behavior.

\section{Neuromodulation of Ant Social Behavior}

\section{Reproductive Dominance and Colony Foundation}

The distinction between the nonreproductive (worker) caste and the fertile (queen) caste is a defining feature of eusociality. Queenless ant species - those in which reproductive and worker forms are not morphologically well differentiated - are particularly insightful to study the neuromodulation of behaviors related to fertility and reproductive status because all females develop as reproductively capable workers. Dominance hierarchies among colony members in queenless ants, and thus reproductive or worker roles, are created by outcomes of conflict. Through aggressive confrontations, the most dominant female becomes the sole reproductive, or queen, in a colony. A variety of studies have explored the involvement of monoamines in reproductive dominance in ants. In H. saltator, expression of dopaminergic and serotonergic fibers was found to be independent of reproductive state, suggesting that neural architecture is unaffected by fertility and social hierarchy in this species [Hoyer et al., 2005]. However, in Streblognathus peteersi, dominant females have higher OA titers indicating OA involvement in ovarian activity [Cuvillier-Hot and Lenoir, 2006]. DA can also be positively correlated with reproductive behavior in insects [Neckameyer, 1998; Boulay et al., 2001; Sasaki et al., 2007]. In gynes of the fire ant Solenopsis invicta, high levels of DA are associated with asexual reproduction [Boulay et al., 2001]. Higher levels of DA are correlated with increased dealation, the shedding of wings that occurs during colony foundation, and growth of oocytes in gynes separated from a queen. 
Production of oocytes and haploid egg laying, but not dealation, can be decreased by treatment with a tyrosine hydroxylase inhibitor, which leads to lowered DA titers. In honeybees, queen mandibular pheromone reduces DA levels of young workers inside the nest; decreased DA reduces locomotion, which may increase worker brood care [Beggs et al., 2007]. Thus, the actions of OA and DA may both be involved in reproductive division of labor and, more broadly, in worker task attendance.

Queen insemination is followed by significant physiological, anatomical, and behavioral changes, including reduction of brain regions [Julian and Gronenberg, 2002], induction of cooperation or competitive aggression [Aron et al., 2009], maternal care [Mas and Kölliker, 2008], and fertility signaling [Peeters and Liebig, 2009]. In Formica japonica queens, levels of DA, 5-HT, and OA in the brain decrease after mating, while tyramine increases [Aonuma and Watanabe, 2012a]. Tyramine, the precursor to OA often considered a signaling molecule in its own right [Roeder, 2005], may be involved in reproduction [as in honeybees; Salomon et al., 2012], but it is unclear whether the decrease in other biogenic amines is due to the act of mating itself or to other behavioral changes such as the completion of flight activity and dealation or isolation from nestmates, which are both temporally coincident with mating. The observed decrease in DA could also be due to starvation stress [Wada-Katsumata et al., 2011], as claustrally founding queens establish colonies without access to food, relying only on their own energy reserves to provision the first brood. OA may decrease throughout a queen's life, corresponding with either reproductive activities or social environment [Wada-Katsumata et al., 2011]. In addition to a decrease after mating as in F. japonica queens [Aonuma and Watanabe, 2012a], established Messor pergandei queens have less OA than do foundresses [Muscedere et al., in preparation]. Biogenic amines in gynes increase during 10 days of isolation [Aonuma and Watanabe, 2012a], suggesting that biogenic amines likely play a role in the transition from virgin status to a mated, colony-founding queen, but it is unknown how mating and the accompanying physiological changes are controlled or affect biogenic amine titers.

\section{Worker Polymorphism and Task Specialization}

The majority of ant species have a monomorphic worker caste in which worker size variation is low. In a relatively small number of ant species, however, multiple worker subcastes differentiated by morphology and body size perform different tasks. Studies of the organization of division of labor in ants feature Pheidole [Traniello,
2010], renowned for its hyperdiversity, prevalence, and striking subcaste specializations, which are hypothesized to have been key to the adaptive radiation of this genus [Wilson, 2003]. The majority of Pheidole species exhibit complete dimorphism in the worker caste (fig. 2a); major workers are relatively large in body size and have disproportionately large heads, adaptations that improve their fighting or food processing ability but compromise behavioral plasticity [Mertl and Traniello, 2009]. Minor workers, in comparison, are smaller and more morphologically uniform task generalists. Biogenic amine titers, scaled for brain size variation, may differ among subcastes, suggesting a role in modulating division of labor in relation to caste polyphenism. 5-HT and DA titers, for example, are significantly higher in $P$. dentata major worker brains than in minor worker brains [Giraldo and Traniello, unpubl. obs.] and may influence major worker defensive behaviors.

The coupling of worker body size, task specialization, brain structure, and monoamines is illustrated by leaf-cutter ants, which have a coevolutionary relationship with symbiotic fungi and bacteria [Schultz and Brady, 2008]. Atta form colonies of potentially millions of strongly polymorphic workers $(0.8-3.5 \mathrm{~mm}$ in head width; fig. $2 \mathrm{~d})$ that divide tasks associated with leaf collection and the culturing of a mutualistic fungus according to body size [Wilson, 1980]. Tiny minim workers implant fungal hyphae and care for brood (fig. 2b), slightly larger media workers dispose of colony waste, larger workers gather leaves that are reduced to mulch to cultivate fungus (fig. $2 \mathrm{c}$ ), and the largest major workers engage solely in defense [Wilson, 1980; Camargo et al., 2007; Waddington and Hughes, 2010]. Following Haller's rule, which notes that smaller individuals have brains that are large relative to their body compared to individuals of a larger body size, smaller Atta columbica workers have relatively larger brains than do larger workers despite miniaturization of body size [Seid et al., 2011]. Brain scaling in minim workers, however, does not follow the same slope as that of larger ants; minims therefore have relatively smaller brains, perhaps due to energetic costs or morphological constraints. Similar brain-to-body scaling trends are found in A. cephalotes (fig. 5a). Analyses of brain DA and 5-HT content show a single allometric relationship between biogenic amine titers and brain mass, indicating that biogenic amines do not scale diphasically as does body size. Instead, these data suggest a 1:1 relationship between monoamine level and the absolute amount of neural tissue (fig. 5b). An energetic cost constraint on brain size [Seid et al., 2011; van der Woude et al., 2013] could result in smaller workers having 


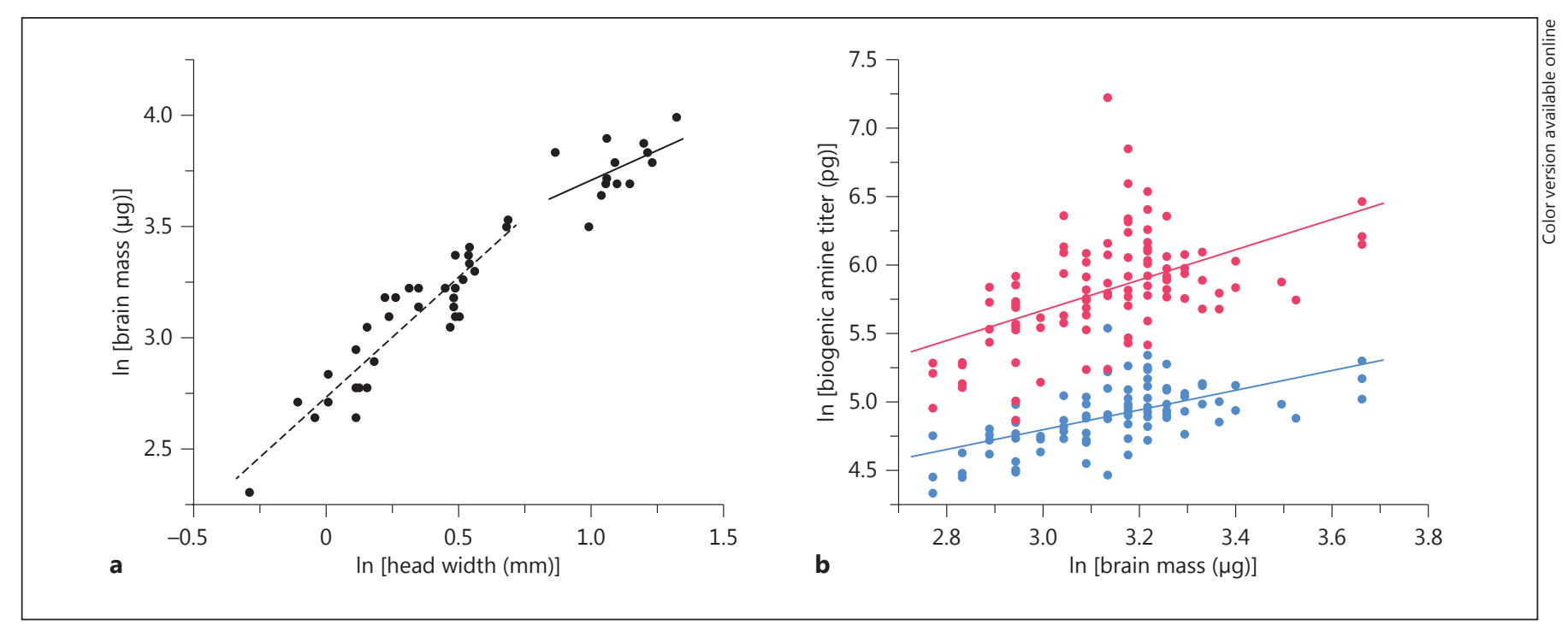

Fig. 5. Brain scaling relationships in the leaf cutter ant $A$. cephalotes. a Diphasic relationship between head width and brain mass in workers [larger: $\mathrm{y}=0.53 \mathrm{x}+3.17\left(\mathrm{R}^{2}=0.25\right.$, solid line); smaller: $\mathrm{y}=1.08 \mathrm{x}+2.73\left(\mathrm{R}^{2}=0.85\right.$, dashed line)]. b DA (red) and 5-HT (blue) titers correlate with brain mass throughout the polymorphic range of workers $\left[\mathrm{DA}: \mathrm{y}=1.11 \mathrm{x}+9.99\left(\mathrm{R}^{2}=0.27\right) ; 5-\mathrm{HT}: \mathrm{y}=0.72 \mathrm{x}+7.60\left(\mathrm{R}^{2}=0.37\right)\right]($ colors refer to the online version only).

relatively smaller brains than would be predicted. Brain size could, in turn, limit the amount of biogenic amine production in A. cephalotes workers due to limited availability of precursors and energy costs of neural signaling. The energetic cost of signaling increases at a greater rate than performance in fly photoreceptors [Niven et al., 2007]; the costs of increased aminergic signaling could similarly outweigh the benefits of greater processing capability. Decreased energy availability associated with a smaller brain size could limit the sustained neural firing capacity [Niven and Farris, 2012], thus rendering the smallest workers physiologically incapable of having relatively higher levels of monoamine signaling per brain mass than larger workers.

Little is known about how amines scale with brain size and how variation in task performance is correlated with variation in monoamine titers. In the leaf-cutter Acromyrmex echinatior, a crucial function of division of labor is the reduction of fungal comb contamination by pathogens or toxic substances in waste [Waddington and Hughes, 2010]. Biogenic amine levels positively correlate with body size in A. echinatior, but DA and OA titers are significantly higher in foragers than in midden workers of the same size range, suggesting that amine levels correlate with task specificity [Smith et al., 2013]. 5-HT is similar between midden workers and foragers in this spe- cies. However, 5-HT appears to increase sensitivity to odors of decomposition in midden workers in the closely related A. octospinosus [Muscedere and Traniello, unpubl. obs.]. All three biogenic amines may play an integral role in waste management role differentiation.

\section{Behavioral Development, Task Repertoire Expansion,} and Temporal Polyethism

Temporal polyethism is division of labor related to worker age. The typical progression of task attendance is initiated after adult eclosion with the performance of inside-nest tasks. As adults mature they transition to tasks outside the nest that appear more cognitively demanding, such as searching for and collecting food and defending territory. These extranidal tasks require greater biomechanical and locomotory skills as well as perception and processing of multimodal stimuli. In $P$. dentata, minor workers begin to forage at roughly 3 weeks of age while retaining their role as nurses and improving their ability to care for brood [Seid and Traniello, 2006; Muscedere et al., 2009, 2013]. Mature minor workers respond to signals and cues associated with both inner-nest tasks such as nursing and stimuli associated with predation and scavenging outside the nest, as opposed to responding sequentially to discrete sets of task-related stimuli. Agerelated repertoire expansion appears to have a neuronal 
basis: the mushroom bodies and antennal lobes of $P$. dentata minor workers increase in size [Muscedere and Traniello, 2012] and synaptic boutons decrease in number but enlarge and increase in volume and vesicle number [Seid et al., 2005]. Studies of microglomeruli - synaptic clusters formed between afferent sensory projection neurons and efferent mushroom body Kenyon cells in the mushroom body calyces - show that plasticity in neural architecture may be accompanied by changes in signaling molecules. As honeybee workers age and gain sensory experience, the density of microglomeruli decreases as their size increases, indicating growth in dendritic processes and strengthening of select synapses [Groh et al., 2012]. Associated increases in ribbon synapses in the postsynaptic portion of the microglomeruli suggest increased rates of neurotransmitter release. Neuroplastic changes associated with the development of behavioral capabilities may be reliant on experience-dependent [Stieb et al., 2012] and experience-expectant processes [Fahrbach et al., 1998] and may be accompanied by changes in neurotransmitter synthesis and release.

Although OA titers increase in the worker brain as honeybees age and begin to forage and are causally linked to polyethism [Schulz et al., 2002], few studies correlate age-related division of labor to brain levels of monoamines in ants or causally link neurochemistry and behavior. In $P$. dentata, 5-HT and DA levels increase significantly with minor worker age; OA levels remain constant [Seid and Traniello, 2005]. Increasing brain monoamine levels in 20-day-old individuals coincide with the transition from inside to outside-nest tasks. Moreover, 5-HT appears to control olfactory sensitivity to trail pheromone: $P$. dentata minor workers with pharmacologically decreased 5-HT initiated following behavior on an artificial trail fewer times and followed the trail for shorter distances than did control minors [Muscedere et al., 2012]. These findings indicate that 5-HT is an important neuromodulator of age-related behavior. In $S$. peetersi, DA may be involved in foraging: comparisons of biogenic amine levels among fertile dominant ants, young gynes, and subordinate workers that become foragers show that subordinate workers have significantly higher levels of brain DA [Cuvillier-Hot and Lenoir, 2006]. Because these workers are older, their brain DA may increase with age and regulate their behavior. Alternatively, the DA increase could be due to their subordinate status within the colony.

Mature workers can be induced to perform tasks generally performed by younger workers [Seid and Traniello, 2006], raising questions concerning the role of mono- amines in the regulation of social plasticity. In Formica polyctena, analyses of biogenic amine levels showed significantly higher titers of $\mathrm{OA}$ and a nonsignificant trend toward lower DA in nurses than in foragers and foragers that engage in brood care following exposure to brood in the absence of young workers [termed 'reverted nurses'; Wnuk et al., 2010]. However, it is unclear whether individuals considered to be reverted nurses were actually altering their behavior. Perhaps nursing simply remains in the repertoire of mature worker behavior and therefore the trend toward changes in OA and DA levels recorded in foragers and reverted nurses could be more parsimoniously explained by a general age-related change in amine levels, as occurs in $P$. dentata in association with the expansion of task attendance [Seid and Traniello, 2005].

\section{Social Food Flow}

The nutritional status of individual workers and the colony as a whole is mediated in part by trophallaxis, the exchange and distribution of liquid food and nutrients among workers, between workers and the queen, and between workers and larvae. 5-HT and DA have been implicated in food intake and nutrition-related trophallaxis. Camponotus mus workers fed 5-HT consumed less sucrose solution than did controls in contexts of individual and group feeding [Falibene et al., 2012]. These authors also showed the presence of 5-HT immunoreactivity in the crop and proventriculus, alimentary organs that store liquid food and control bidirectional pumping through valves to take in and regurgitate liquids, indicating that 5-HT regulates trophallaxis.

DA may play a role as well: F. japonica workers show lower DA levels and decreased trophallaxis after 7 days of starvation [Wada-Katsumata et al., 2011]. After consuming a solution of sucrose, trophallaxis was reinstated and DA increased. DA may be associated with satiation, which occurs following the distribution of food: lower titers of DA are found in brood-deprived P. dentata minor workers, possibly due to not having brood to provide nutrition [Kloppenburg and Hilderbrand, 1995; Muscedere et al., 2013]. However, in F. japonica, DA returned to control levels only after trophallaxis, suggesting its level may be modulated by both social interaction and nutritional state [Wada-Katsumata et al., 2011]. It is unclear whether DA levels would return to control levels in the absence of trophallaxis if workers were allowed more time for digestion. On this point, Wada-Katsumata et al. [2011] showed that 3 and 5 min after imbibing a sucrose solution, levels of DA were stable, suggesting that DA may be implicated in food intake and trophallaxis. However, DA titers de- 
creased, rather than increased as in the prior observation, from titers measured in the absence of sucrose feeding, indicating that the precise role of DA requires resolution in this system.

\section{Predatory Aggression}

One context in which aggression can occur is foraging: ants are important predators of arthropods, including other social insects and, sometimes, small vertebrates. Few studies identify a role for biogenic amines in predatory aggression. In $P$. dentata, 5-HT does not modulate aggression toward fruit flies used as experimental prey [Giraldo et al., unpubl. obs.]. Aonuma and Watanabe [2012b] suggest that OA is involved in prey capture by $F$. japonica foragers due to correlational differences between aggression and the ratio of $\mathrm{OA}$ to $\mathrm{OA}$ catabolite $\mathrm{N}$-acetyloctopamine in queens and workers. However, workers also have higher titers of 5-HT and DA and lower levels of tyramine than do queens, which do not typically forage. It is therefore unclear whether these signaling molecules play a role in predatory aggression or are associated with other physiological differences between workers and queens.

\section{Nestmate Recognition}

The ability to distinguish nestmates from nonnestmate conspecific and heterospecific ants is crucial to the social cohesiveness of a colony and its ability to defend the nest and territory. Ecological interactions among ants may involve aggressive confrontations among colonies resulting in unoccupied buffer zones ('no ants land') between adjacent territories. Territorial disputes are mediated by nestmate recognition systems that may have species and/or colony specificity [Newey et al., 2010]. Nestmate recognition systems have traditionally been analyzed by recording the frequency and level of aggressive responses to nonnestmates [Blomquist and Bagnères, 2010]. Cuticular hydrocarbons found on the exoskeleton surface serve as recognition signals [Blomquist and Bagnères, 2010; Sturgis and Gordon, 2012] and can be transferred by allogrooming and trophallaxis. Cuticular hydrocarbons providing cues for nestmate recognition are detected by olfactory processing in antennal receptors and the antennal lobes [Stroeymeyt et al., 2010; Brandstaetter et al., 2011].

OA, which improves nestmate recognition in honeybees [Robinson et al., 1999], appears to serve a similar neuromodulatory role in the fire ant $S$. invicta [Vander Meer et al., 2008]. OA levels are correlated with levels of aggression directed toward conspecifics that change with

Neuromodulation of Social Behavior in Ants the presence of a queen. Of 3 treatment groups (queenless workers, queenless workers fed $\mathrm{OA}$, and queenright workers), OA levels were highest in workers administered $\mathrm{OA}$, and these were similar to those of workers in queenright groups. OA levels were significantly lower in workers in the untreated queenless group, suggesting that $\mathrm{OA}$ is maintained at high levels in the presence of the queen possibly due to pheromonal cues [Beggs et al., 2007]. Queens do not appear to directly provide the cues needed for nestmate recognition because they produce significantly lower amounts of hydrocarbons than do workers and hydrocarbon transfer is primarily from worker to queen [Howard and Blomquist, 2005]. Queenright workers showed significantly more aggression toward nonnestmates than did queenless groups, and OA-treated queenless workers, while initially exhibiting aggression levels similar to those of queenless controls, increased their aggression to levels similar to those of queenright workers over a 10 -week period. Therefore, decreased aggression (and hence nestmate discrimination) due to losing a queen may be caused by a decrease in OA.

OA may enhance aggressive responses in the Australian weaver ant Oecophylla smaragdina as well. Nestmate recognition, as noted, is a mechanism associated with territorial defense. In O. smaragdina, workers are in effect dimorphic: minor workers remain within leaf nests and care for brood, whereas major workers patrol territory, attack intruders, and harvest food. Major workers show higher levels of territorial aggression than minor workers and have significantly higher levels of OA [Kamhi and Traniello, unpubl. obs.]. These results suggest that OA induces aggressive responses to alien ants or increases discrimination of nonnestmates, corroborating studies implicating OA in aggression in Drosophila [Zhou et al., 2008] and crickets [Stevenson and Schildberger, 2013].

In C. fellah, experimentally isolated workers appear to lose their colony-specific chemical signatures, but reassimilation into their parent colony may be facilitated by trophallactic exchanges. OA may be involved in the regulation of this isolation-induced trophallaxis [Boulay et al., 2000]. Ants isolated for 5 days and administered a high dose of OA exhibited trophallaxis for short durations, similar to those of nonisolated controls, whereas isolated control workers engaged in significantly longer durations of trophallaxis. Brain titers of monoamines were not quantified in these experiments to confirm the effect of pharmacological manipulations on OA levels. However, administration of phentolamine, an OA antagonist, returned durations of trophallactic exchanges to isolation control levels when given in combination with $\mathrm{OA}$, sug- 
gesting that decreasing OA titers does increase isolationinduced trophallaxis. In F. japonica, however, OA had the opposite effect and increased the rate of trophallaxis after workers were isolated for 2 days [Wada-Katsumata et al., 2011]. In this species, OA could be reduced to control levels after contact with nestmates. These apparently opposing actions of $\mathrm{OA}$ in closely related species accentuate the need for further investigations.

\section{Collective Intelligence: Neuromodulation of Individual Behavior and the Organization of Group Decision Making}

Cooperative behaviors allow a colony to respond to environmental challenges that individual workers cannot effectively meet by acting alone. The collective intelligence of a colony - its capacity for accurate and precise group decision making - is hypothesized to emerge from interactions which integrate the activities of simple individuals following basic behavioral algorithms [Camazine et al., 2001]. Relying only on local information shared through communication signals, colonies behave as cohesive units, reducing individual errors and rendering rapid decisions despite the limited knowledge and experience of the individual workers comprising the group. Workers lack an understanding of the global, fitness-enhancing objective, but they nevertheless assemble collective actions through self-organization. The relationship of social interactions, colony-level behavior, and the neuromodulation of individual worker behavior is poorly understood.

Cooperative foraging in ants, one commonly studied system of collective intelligence, requires the behavioral integration of potentially thousands of workers to make adaptive decisions that maximize colony nutritional intake by harvesting the most profitable food resources or minimize energetic expenditures by selecting shorter foraging routes [Garnier et al., 2009]. The role of monoamines in such collective behavior can be appreciated from an analysis of recruitment communication, which is initiated following the discovery of a new food source [reviewed in Hölldobler and Wilson, 1990]. Workers unaware of the location of the food source are first recruited from the nest to assist in retrieving food; the number of workers arriving at the food source increases as more workers are recruited, and the food is eventually depleted or the colony becomes sated. Foraging then ceases.

The social organization of food recruitment and foraging varies among ant species and includes basal and derived signaling systems. Tandem running is a simple form of recruitment communication, where a successful scout returns to the nest and leads a single nestmate to a new food source [Möglich et al., 1974]. Physical contact and surface pheromones on the gaster of the leading ant maintain tandem movement by the pair. In group recruitment, an activating motor display delivered directly to nestmates upon contact in the nest and a trail pheromone that provides only an orientation cue are social signals required in combination to recruit ants. Mass recruitment, considered to be the most highly evolved mode of chemical recruitment communication in ants, involves the deposition of a pheromone trail between the food source and the nest; the chemical properties of the trail encode information necessary to both excite workers to depart from the nest and orient them to the food [Hölldobler and Wilson, 1990]. As trail pheromone evaporates, traffic on the trail decreases, and the recruitment response of the colony and food collection are terminated. In this evolutionary model, nestmate stimulation and orientation are necessary to organize foraging. Either behavioral displays of successful scouts or perception of excitatory components of chemical trails could initiate orientation within the active space of the trail pheromone.

Tactile excitation [Anstey et al., 2009] and/or pheromonal stimulation may cause neurotransmitter release or workers may show age-related changes in neuromodulators to prime ants to initiate foraging [Seid and Traniello, 2005; Seid et al., 2008] or respond to trail pheromones [Muscedere et al., 2012]. DA release, for example, is implicated in arousal in Drosophila [Kume et al., 2005] and leads to increased locomotion, and monoamines are known to modulate olfactory sensitivity [Kloppenburg and Hilderbrand, 1995]. The level of biogenic amines in the brains of individual workers is thus critical to their ability to participate in foraging and is therefore significant in the organization of collective behavior. Aminergic control of task-related sensory responsiveness illustrates one neuroethological mechanism of collective decision making. The role of the metaphorical 'colony brain' in emergent group behavior is therefore at least in part constructed from the neurochemistry of the brains of individual workers.

Couzin [2009] suggested that ant workers are 'mobile neural networks' and described parallels in neuron-like and neural network properties of workers that can be modeled from the characteristics of neurons and neural circuits to understand social network structure. Coordination of actions among ants could be modulated by exposure to different stimuli, stimulus intensities, and interactions among workers coupled physiologically by 
brain monoamine levels. The induction of gregariousness in desert locusts offers a simple model: tactile and visual stimuli from conspecifics increase brain levels of 5-HT, causing the transition from solitary to social life history phases [Anstey et al., 2009]. Locusts thus form a social swarm from solitary individuals due to spatial proximity. Boi et al. [1999] showed that spontaneously active ants can excite inactive ants, leading to cyclical periods of group activity in a nest that are not retained in workers outside the nest. Interactions among ants can lead to initiation of specialized labor within the colony [Duarte et al., 2011]. Such synchronization of worker activity may be comparable to neuronal synchronization [Couzin, 2009]: spontaneously firing neurons form an oscillating neuronal network creating cyclical periods of increased sensory processing [Buzsáki and Draguhn, 2004]. We hypothesize that interactions among workers may cause neuronlike synchronization of behaviors that in turn synchronize monoamine titers in workers and contribute to the coordination of collective behavior. This neuromodulatory sychronization could lead to the alignment of worker behavior to format group activity. Some ants could act as 'pacemaker neurons', setting periods of cyclical activity [Boi et al., 1999] and synchronizing biogenic amine titers. For example, when a successful forager returns to the nest, DA, perhaps in conjunction with 5-HT, could be activated to synchronize trail pheromone responsiveness among workers having variable thresholds and thus coordinate the foraging effort. Synchronization of neurotransmitter release occurs in vertebrate brains [PaceSchott and Hobson, 2002] and can be internally driven from the oscillating system or externally driven from a neural center [Buzsáki, 2006]. Neural synchronization could parallel collective action within an ant colony. Driven by external sensory stimuli or internal 'pacemaker' ants, monoamines could become synchronized within a group of ants and lead to coordinated collective action. There is sufficient interindividual variability in worker behavior to support this hypothesis [Robson and Traniello, 1999, 2002].

\section{Research Opportunities}

The analysis of social behavior in ants can clearly benefit from studies of neurochemical regulation that integrate physiology, development, ecology, and evolution and thus provide models for the study of neuromodulation of behavior in animal societies in general. Recent research indicates that biogenic amines regulate several im- portant social behaviors and serve significant functions in the genesis of individual behavior and complex social organization. This work provides a basis for rigorous experimental studies to advance our understanding of the role of monoamines in social organization and the emergence of collective action. Apparent contradictions in some results need to be resolved and key questions remain unanswered. In addition to the social behaviors discussed here that require continued and more detailed investigation, we present 6 additional areas of research that we believe will be highly insightful and productive. We note, however, that we are constrained by a lack of data that would allow the details of the phenomena we suggest be explored to be more readily identified and discussed more thoroughly.

\section{Gene Expression and Neuromodulation of Task}

Performance

Genes that modulate neurotransmitter action have been implicated in the regulation of social behavior in a variety of species [Caspi et al., 2002; Bortolato et al., 2011; Gurel et al., 2012]. Although the upregulation of specific genes in ants has been related to task plasticity [Lucas and Sokolowski, 2009], in situ immunolabeling of monoamine receptors that function in the neuromodulation of task performance are limited to studies on honeybees [Hauser et al., 2006]. Research linking gene expression and neuromodulation in ants will very likely yield results different from those of honeybees because ants are apterous, potentially strongly polymorphic in the worker caste, and diverse in species number and thus the manner in which brain design reflects adaptation. To date, the genomes for 7 ants have been sequenced [Bonasio et al., 2010; Nygaard et al., 2011; Smith et al., 2011a, b; Suen et al., 2011; Wurm et al., 2011], enabling evolutionary analyses of the genetics of social behaviors characteristic of species such as seed-harvesting Pogonomyrmex [Smith et al., 2011b] or activities related to the cultivation of symbiotic fungus in A. cephalotes [Suen et al., 2011] and A. echinatior [Nygaard et al., 2011]. By sequencing the genome of $P$. dentata, a species well studied for its subcasteand age-related division of labor, we can further our understanding of how monoamines modulate task specialization and explore its genetic basis. Characterization of genes involved in the regulation and function of ant biogenic amines will allow the development of pharmacological reagents to facilitate the development of experimental drug treatments and improve their reliability. 
Genetic Diversity, Neuromodulation, and Division of Labor

Sociogenomic approaches to the study of the regulation of ant behavior can address a broad range of questions. Genetic diversity in colonies of different ant species, for example, varies with the degree of polyandry (multiple mating by the queen) and polygyny (the presence of multiple queens in a colony) and is considered beneficial to the efficiency of a colony's ergonomic operations [Waibel et al., 2006]. Behavioral specialization of groups - either castes or worker subcastes and age cohorts - within a colony may reflect genetic variation associated with worker patrilines [Evison and Hughes, 2011; Schluns et al., 2011; Huang et al., 2013; Smith et al., 2013 ] that could code for differences in monoamine synthesis or receptors and thus the neuromodulation of behavior [Donaldson and Young, 2008; Krugel et al., 2009]. Variation in monoamine action could be associated with patrilineal or matrilineal differences in worker response thresholds for task attendance, influencing sensitivity to cues or task-related pheromones and other social signals correlated with division of labor. Exploring intracolony genetic diversity could thus provide insight into the origin of neural and physiological mechanisms of social behavior.

\section{Aminergic Regulation of Size- and Age-Related}

Division of Labor and the Cost of Brain Metabolism

As we have discussed, the evolution of caste- and agerelated behavioral specialization can dramatically reduce worker repertoire size and/or flexibility. This characteristic of ant division of labor is striking when one considers the behavioral multipotency of any solitary insect that searches for a mate, reproduces, forages, and rears offspring independently, and the plasticity of more generalist workers in a colony. Caste-specific behavioral adaptations, therefore, could lower the metabolic costs associated with maintaining expensive neural tissue by reducing brain size and processing regions needed to support behavioral repertoires [Mares et al., 2005]. Reduction in brain tissue could in turn lead to more simplified and specialized aminergic circuitry that either promotes or limits behavioral flexibility. For example, brain monoamine levels could cause increased sensitivity to task-related stimuli such as foraging and, conversely, a decreased ability to respond to stimuli that guide nursing or waste disposal. Our understanding of the relationship of task specialization, aminergic circuitry, and brain metabolism is currently limited.

\section{Aminergic Regulation of Behavioral Syndromes}

Although division of labor is often linked to age and subcaste, consistent individual variation in behavior within a subcaste can also lead to task specialization [Jandt et al., 2013]. Given that the vast majority of ants have a monomorphic worker caste, it is not surprising that behavioral syndromes may be present within colonies and that ants show personality differences (e.g. some workers behave more aggressively than others). Colonies, as well as individual workers, can also exhibit behavioral syndromes, leading to varying abilities in territorial competition and thus access to resources [Jandt et al., 2013]. While the maturity of both individual workers and colonies and genetic variation within and among colonies may be implicated, the mechanisms underlying behavioral syndromes are largely unknown. Exploring the role of biogenic amines in behavioral syndromes will elucidate if and how amines modulate colony-level behavioral variation and worker personalities that are not solely age and subcaste related.

\section{Phylogenetic Analysis of the Modulation of Social Behavior}

Carlson [2012] recently argued that research in behavioral neuroscience - which has predominantly focused on studies of a limited number of traditional model systems - could be made more insightful by evolutionary analysis. The great species richness of ants, which are a single monophyletic and ecologically dominant family [Moreau et al., 2006; Moreau and Bell, 2013], is sparsely represented in the current literature on neuromodulation. All of the species studied fall into only 3 subfamilies (Myrmicinae, Formicinae, and Ponerinae) of a total of 25, leaving most groups unrepresented. Macroevolutionary trends in aminergic control and microevolutionary patterns therefore are currently not possible to identify due to a lack of relevant data. Broadening species sampling, comparing sister clades with contrasting degrees of social complexity, and adding phylogenetic analyses of ant social behavior and its control will allow independent contrasts and offer multiple systems to aid in distinguishing the relationship of aminergic regulation, evolutionary relatedness, ecology, social organization, and functional neuroplasticity. Research in this area has been beneficial in the study of biogenic amines and social decision making in vertebrate lineages [O'Connell and Hofmann, 2012]. In the eusocial Hymenoptera, neuroanatomy has been contrasted in solitary and social bees [Mares et al., 2005], but few studies have examined the evolution of aminergic control of social behavior [Hauser et al., 2006]. It is unknown how ancestral character states relate to de- 
rived functions of monoamines in ants, and how they have differentiated in respect to sociality. Cataglyphis fortis, for example, has served as a neuroethological model for detailed behavioral and neuroanatomical studies of solitary action [Stieb et al., 2010, 2011], but neurochemistry has yet to be explored. Sister clade comparisons between the socially complex weaver ants Oecophylla and various species of Formica, which have strikingly lower degrees of complexity, could provide instructive models for comparative studies. By combining our understanding of the molecular phylogeny of ants [Moreau and Bell, 2013] with sociobiological and neuromolecular data, comparisons can be made across ant genera to reveal neuroethological trends in the evolution of caste division of labor and emergent colony intelligence. It is also possible to more deeply explore the origin of the aminergic control of ant social behavior through comparative studies of solitary wasps that show extensive parental care or other hymenopteran lineages, including semisocial and quasisocial forms, in which females may exhibit diverse and complex repertoires.

\section{Monoamines and Parasite Manipulation of Social Host Behavior}

Diverse parasites use ants as hosts and manipulate worker behavior for their fitness advantage. The fungus Ophiocordyceps unilateralis, for example, infects Camponotus leonardi, causing workers to become 'zombies' and descend from their arboreal nests, become disorientated, and latch onto a leaf in a 'death grip' to promote fungal growth and dispersal [Hughes et al., 2011]. The mechanisms by which parasites alter host behavior may involve quantitative and/or qualitative changes in brain monoamine levels [Skallova et al., 2006; Shaw et al., 2009]. Ant behavior could change due to infection-related mono- amine action caused by immune response to infection or substances of parasite origin that acts on the ant brain to affect neuromodulation. The neurogenetic architectures underscoring these parasite-induced alterations of brain chemistry could also be examined. Exploring parasite host systems and the neuromodulatory mechanisms underlying behavioral manipulation by parasites may also generally elucidate the role of monoamines in ant behavior.

\section{Conclusions}

Ants, as a diverse clade, provide numerous model systems in socioneuroethology. Workers possess relatively simple brain structures that nonetheless give rise to elaborate and adaptive individual and collective behaviors, enabling ants to establish themselves ecologically as 'the little creatures that run the world'. Understanding the role of monoamines in individual and collective actions performed by diverse species of ants can provide insight into the mechanisms by which biogenic amines can adaptively modulate social behavior. Examining neuromodulation in the ant brain will broadly inform our knowledge of mechanisms underlying behavior and neural circuitry.

\section{Acknowledgments}

We thank Alex Wild and Janelle Evans for photograph permissions. We greatly appreciate the helpful discussions and careful editing provided by Dr. Mario L. Muscedere, Ysabel M. Giraldo, and Darcy G. Gordon. N. Frank collected data on Atta. We thank Georg Striedter, Patrizia d'Ettorre, and an anonymous reviewer for their helpful comments on the manuscript. This work was supported by NSF Collaborative Research Grants IOB 0725013 (J.F.A.T.) and 0724591 (W. Gronenberg).

\section{References}

Anderson KE, Munger JC (2003): Effect of temperature on brood relocation in Pogonomyrmex salinus (Hymenoptera: Formicidae). West North Am Nat 63:122-128.

- Anstey ML, Rogers SM, Ott SR, Burrows M, Simpson SJ (2009): Serotonin mediates behavioral gregarization underlying swarm formation in desert locusts. Science 323:627630.

Aonuma H, Watanabe T (2012a): Changes in the content of brain biogenic amine associated with early colony establishment in the queen of the ant, Formica japonica. PLoS One $7: e 43377$

Neuromodulation of Social Behavior in Ants
Barron AB, Robinson GE (2005): Selective modulation of task performance by octopamine in honey bee (Apis mellifera) division of labour. J Comp Physiol A Neuroethol Sens Neural Behav Physiol 191:659-668.

Beggs KT, Glendining KA, Marechal NM, Vergoz V, Nakamura I, Slesoor KN, Mercer AR (2007): Queen pheromone modulates brain dopamine function in worker honey bees. Proc Natl Acad Sci USA 104:2460-2464.

Baier A, Wittek B, Brembs B (2002): Drosophila as a new model organism for the neurobiology of aggression? J Exp Biol 205:1233-1240. gic system in the brain controls aggressive Biol Hung 63:63-68. ternity apportionment on the outcome of fights in cooperative foundations of the ant
Beshers SN, Fewell JH (2001): Models of division of labor in social insects. Annu Rev Entomol 46:413-440. 
Billen J, Morgan ED (1998): Pheromone communication in social insects: sources and secretions; in Vander Meer RK, Breed MD, Espelie $\mathrm{KE}$, et al (eds): Pheromone Communication in Social Insects: Ants, Wasps, Bees, and Termites. Boulder, Westview Press, 3-33.

Blomquist GJ, Bagnères A (2010): Insect Hydrocarbons: Biology, Biochemistry, and Chemical Ecology. Cambridge, Cambridge University Press.

Boi S, Couzin ID, Del Buono N, Franks NR, Britton NF (1999): Coupled oscillators and activity waves in ant colonies. Proc R Soc B Biol Sci 266:371-378.

Bonasio R, Zhang GJ, Ye CY, Mutti NS, Fang XD, Qin N, Donahue G, Yang PC, Li QY, Li C, Zhang P, Huang ZY, Berger SL, Reinberg D, Wang J, Liebig J (2010): Genomic comparison of the ants Camponotus floridanus and Harpegnathos saltator. Science 329:1068-1071.

- Bortolato M, Chen K, Godar SC, Chen G, Wu W, Rebrin I, Farrell MR, Scott AL, Wellman CL, Shih JC (2011): Social deficits and perseverative behaviors, but not overt aggression, in MAO-A hypomorphic mice. Neuropsychopharmacology 36:2674-2688.

-Boulay R, Hooper-Bui LM, Woodring J (2001): Oviposition and oogenesis in virgin fire ant females Solenopsis invicta are associated with a high level of dopamine in the brain. Physiol Entomol 26:294-299.

- Boulay R, Soroker V, Godzinska EJ, Hefetz A, Lenoir A (2000): Octopamine reverses the isolation-induced increase in trophallaxis in the carpenter ant Camponotus fellah. J Exp Biol 203:513-520.

Brandstaetter AS, Kleineidam CJ (2011): Distributed representation of social odors indicates parallel processing in the antennal lobe of ants. J Neurophysiol 106:2437-2449.

-Brandstaetter AS, Rössler W, Kleineidam CJ (2011): Friends and foes from an ant brain's point of view - neuronal correlates of colony odors in a social insect. PLoS One 6:e21383.

Brian MV (1975): Larval recognition by workers of the ant Myrmica. Anim Behav 23:745-756.

Buzsáki G (2006): Rhythms of the Brain. New York, Oxford University Press.

Buzsáki G, Draguhn A (2004): Neuronal oscillations in cortical networks. Science 304:19261929.

-Camargo RS, Forti LC, Lopes JFS, Andrade APP, Ottati ALT (2007): Age polyethism in the leafcutting ant Acromyrmex subterraneus brunneus Forel, 1911 (Hym., Formicidae). J Appl Entomol 131:139-145.

Camazine S, Deneubourg JL, Franks N, Sneyd J, Theraulaz G, Bonabeau E (2001): Self-organization in biological systems. Princeton, Princeton University Press.

Carlson BA (2012): Diversity matters: the importance of comparative studies and the potential for synergy between neuroscience and evolutionary biology. Arch Neurol 69:987-993.
Caspi A, McClay J, Moffit TE, Mill J, Martin J (2002): Role of genotype in the cycle of violence in maltreated children. Science 297: 851-854.

Chittka L, Niven J (2009): Are bigger brains better? Curr Biol 19:R995-R1008.

Christensen TA, Lehman HK, Teal PEA, Itagaki H, Tumlinson JH, Hildebrand JG (1992): Diel changes in the presence and physiological actions of octopamine in the female sex-pheromone glands of Heliothine moths. Insect Biochem Mol Biol 22:841-849.

Cotoneschi C, Scognamiglio F, Scala C, Cervo R, Strassmann JE, Turillazzi S (2007): Larval sex identification in the paper wasp Polistes dominulus (Vespidae, Hymenoptera). Insectes Soc 54:132-135.

Couzin ID (2009): Collective cognition in animal groups. Trends Cogn Sci 13:36-43.

Cuvillier-Hot V, Lenoir A (2006): Biogenic amine levels, reproduction and social dominance in the queenless ant Streblognathus peetersi. Naturwissenschaften 93:149-153.

Darwin C (1871): The descent of man, and selection in relation to sex. London, Murray.

den Boer SPA, Duchateau MJHM (2006): A larval hunger signal in the bumblebee Bombus terrestris. Insectes Soc 53:369-373.

Donaldson ZR, Young LJ (2008): Oxytocin, vasopressin, and the neurogenetics of sociality. Science 322:900-904.

Duarte A, Weissing FJ, Pen I, Keller L (2011): An evolutionary perspective on self-organized division of labor in social insects. Annu Rev Ecol Evol Syst 42:91-110.

-Dunbar RIM, Shultz S (2007): Evolution in the social brain. Science 317:1344-1347.

Eberhard WG, Wcislo WT (2012): Plenty of room at the bottom? Tiny animals solve problems of housing and maintaining oversized brains, shedding new light on nervous-system evolution. Am Sci 100:226-233.

Evison SE, Hughes WO (2011): Genetic caste polymorphism and the evolution of polyandry in Atta leaf-cutting ants. Naturwissenschaften 98:643-649.

Fahrbach SE (2006): Structure of the mushroom bodies of the insect brain. Annu Rev Entomol 51:209-232.

Fahrbach SE, Moore D, Capaldi EA, Farris SM, Robinson GE (1998): Experience-expectant plasticity in the mushroom bodies of the honeybee. Learn Mem 5:115-123.

Falibene A, Rössler W, Josens R (2012): Serotonin depresses feeding behaviour in ants. J Insect Physiol 58:7-17.

Garnier S, Guérécheau A, Combe M, Fourcassié V, Theraulaz G (2009): Path selection and foraging efficiency in Argentine ant transport networks. Behav Ecol Sociobiol 63:11671179.

- Giraldo YM, Patel E, Gronenberg W, Traniello JF (2013): Division of labor and structural plasticity in an extrinsic serotonergic mushroom body neuron in the ant Pheidole dentata. Neurosci Lett 534:107-111.
Giurfa M (2006): Associative learning: the instructive function of biogenic amines. Curr Biol 16:R892-R895.

Gordon DM (2010): Ant Encounters: Interaction Networks and Colony Behavior. Princeton, Princeton University Press.

Groh C, Lu ZY, Meinertzhagen IA, Rössler W (2012): Age-related plasticity in the synaptic ultrastructure of neurons in the mushroom body calyx of the adult honeybee Apis mellifera. J Comp Neurol 520:3509-3527.

Groh C, Rössler W (2011): Comparison of microglomerular structures in the mushroom body calyx of neopteran insects. Arthropod Struct Dev 40:358-367.

Gronenberg W (1996): Neuroethology of ants. Naturwissenschaften 83:15-27.

Gronenberg W (2001): Subdivisions of hymenopteran mushroom body calyces by their afferent supply. J Comp Neurol 435:474-489.

Gronenberg W (2008): Structure and function of ant (Hymenoptera: Formicidae) brains: strength in numbers. Myrmecol News 11:2536.

Gurel G, Gustafson MA, Pepper JS, Horvitz HR, Koelle MR (2012): Receptors and other signaling proteins required for serotonin control of locomotion in Caenorhabditis elegans. Genetics 192:1359-1371.

-Hauser F, Cazzamali G, Williamson M, Blenau W, Grimmelikhuijzen CJP (2006): A review of neurohormone GPCRs present in the fruitfly Drosophila melanogaster and the honey bee Apis mellifera. Prog Neurobiol 80:1-19.

Hölldobler B, Wilson EO (1990): The Ants. Cambridge, Harvard University Press.

Hölldobler B, Wilson EO (2009): The Superorganism: The Beauty, Elegance, and Strangeness of Insect Societies. New York, Norton.

Howard RW, Blomquist GJ (2005): Ecological, behavioral, and biochemical aspects of insect hydrocarbons. Annu Rev Entomol 50:371393.

Hoyer SC, Liebig, Liebig J, Rössler W (2005): Biogenic amines in the ponerine ant Harpegnathos saltator: serotonin and dopamine immunoreactivity in the brain. Arthropod Struct Dev 34:429-440.

Hoyle G (1985): Generation of motor activity and control of behaviour: the role of the neuromodulator octopamine and the orchestration hypothesis; in Kerkut GA, Gilbert L (eds): Comparative Insect Physiology, Biochemistry and Pharmacology. Toronto, Pergamon Press, vol 5, 607-621.

-Huang MH, Wheeler DE, Fjerdingstad EJ (2013): Mating system evolution and worker caste diversity in Pheidole ants. Mol Ecol 22:19982010.

Huber R (2005): Amines and motivated behaviors: a simpler systems approach to complex behavioral phenomena. J Comp Physiol A Neuroethol Sens Neural Behav Physiol 191: 231-239. 
-Huber R, Orzeszyna M, Pokorny N, Kravitz EA (1997): Biogenic amines and aggression: experimental approaches in crustaceans. Brain Behav Evol 50:60-68.

-Hughes DP, Andersen SB, Hywel-Jones NL, Himaman W, Billen J, Boomsma JJ (2011): Behavioral mechanisms and morphological symptoms of zombie ants dying from fungal infection. BMC Ecol 11:13.

- Jandt JM, Bengston S, Pinter-Wollman N, Pruitt JN, Raine NE, Dornhaus A, Sih A (2013): Behavioural syndromes and social insects: personality at multiple levels. Biol Rev Camb Philos Soc DOI: 10.1111/brv.12042.

-Julian GE, Gronenberg W (2002): Smaller brains in queen ants. Brain Behav Evol 60:152-164.

-Kleineidam CJ, Ruchty M, Casero-Montes ZA, Roces $\mathrm{F}$ (2007): Thermal radiation as a learned orientation cue in leaf-cutting ants (Atta vollenweideri). J Insect Physiol 53:478-487.

Kloppenburg P, Hilderbrand JG (1995): Neuromodulation by 5 -hydroxytryptamine in the antennal lobe of the sphinx moth Manduca sexta. J Exp Biol 198:603-611.

Kravitz EA, Huber R (2003): Aggression in invertebrates. Curr Opin Neurobiol 13:736-743.

- Krugel LK, Biele G, Mohr PN, Li SC, Heekeren HR (2009): Genetic variation in dopaminergic neuromodulation influences the ability to rapidly and flexibly adapt decisions. Proc Natl Acad Sci USA 106:17951-17956.

- Kume K, Kume S, Park SK, Hirsh J, Jackson FR (2005): Dopamine is a regulator of arousal in the fruit fly. J Neurosci 25:7377-7384.

Libbrecht R, Schwander T, Keller L (2011): Genetic components to caste allocation in a multiple-queen ant species. Evolution 65:29072915.

Libersat F, Pflueger HJ (2004): Monoamines and the orchestration of behavior. Bioscience 54 : $17-25$.

-Lucas C, Sokolowski MB (2009): Molecular basis for changes in behavioral state in ant social behaviors. Proc Natl Acad Sci USA 106:63516356.

Mares S, Ash L, Gronenberg W (2005): Brain allometry in bumblebee and honey bee workers. Brain Behav Evol 66:50-61.

Mas F, Kölliker M (2008): Maternal care and offspring begging in social insects: chemical signalling, hormonal regulation and evolution. Anim Behav 76:1121-1131.

Mertl AL, Traniello JFA (2009): Behavioral evolution in the major worker subcaste of twignesting Pheidole (Hymenoptera: Formicidae): does morphological specialization influence task plasticity? Behav Ecol Sociobiol 63: 1411-1426.

Möglich M, Maschwitz U, Hölldobler B (1974): Tandem calling: a new kind of signal in ant communication. Science 186:1046-1047.

Moreau CS, Bell CD (2013): Testing the museum versus cradle tropical biological diversity hypothesis: phylogeny, diversification, and ancestral biogeographic range evolution of the ants. Evolution DOI: 10.1111/evo.12105.
Moreau CS, Bell CD, Vila R, Archibald SB, Pierce NE (2006): Phylogeny of the ants: diversification in the age of angiosperms. Science 312: 101-104.

Muscedere ML, Djermoun A, Traniello JFA (2013): Brood-care experience, nursing performance, and neural development in the ant Pheidole dentata. Behav Ecol Sociobiol 67: 775-784.

Muscedere ML, Johnson N, Gillis BC, Kamhi JF, Traniello JFA (2012): Serotonin modulates worker responsiveness to trail pheromone in the ant Pheidole dentata. J Comp Physiol A Neuroethol Sens Neural Behav Physiol 198: 219-227.

Muscedere ML, Traniello JFA (2012): Division of labor in the hyperdiverse ant genus Pheidole is associated with distinct subcaste- and agerelated patterns of worker brain organization. PLoS One 7:e31618.

-Muscedere ML, Traniello JFA, Gronenberg W (2011): Coming of age in an ant colony: cephalic muscle maturation accompanies behavioral development in Pheidole dentata. Naturwissenschaften 98:783-793.

-Muscedere ML, Willey TA, Traniello JFA (2009): Age and task efficiency in the ant Pheidole dentata: young minor workers are not specialist nurses. Anim Behav 77:911-918.

Neckameyer WS (1998): Dopamine modulates female sexual receptivity in Drosophila melanogaster. J Neurogenet 12:101-114.

Neckameyer WS, Leal SM (2009): Biogenic amines as circulating hormones in insects. Horm Brain Behav 2:967-1002.

Newey PS, Robson SKA, Crozier RH (2010): Weaver ants Oecophylla smaragdina encounter nasty neighbors rather than dear enemies. Ecology 91:2366-2372.

Niven JE, Anderson JC, Laughlin SB (2007): Fly photoreceptors demonstrate energy-information trade-offs in neural coding. PLoS One Biol 5:e116.

Niven JE, Farris SM (2012): Miniaturization of nervous systems and neurons. Curr Biol 22:R323-R329.

Niven JE, Graham CM, Burrows M (2008): Diversity and evolution of the insect ventral nerve cord. Annu Rev Entomol 53:253-271.

Nygaard S, Zhang GJ, Schiott M, Li C, Wurm Y, Hu HF, Zhou JJ, Ji L, Qiu F, Rasmussen M, Pan HL, Hauser F, Krogh A, Grimmelikhuijzen CJP, Wang J, Boomsma JJ (2011): The genome of the leaf-cutting ant Acromyrmex echinatior suggests key adaptations to advanced social life and fungus farming. Genome Res 21:1339-1348.

O'Connell LA, Hofmann HA (2012): Evolution of a vertebrate social decision-making network. Science 336:1154-1157.

-Orchard I, Ramirez JM, Lange AB (1993): A multifunctional role for octopamine in locust flight. Annu Rev Entomol 38:227-249.

Pace-Schott EF, Hobson JA (2002): The neurobiology of sleep: genetics, cellular physiology and subcortical networks. Nat Rev Neurosci 3:591-605.
Peeters C, Liebig J (2009): Fertility signaling as a general mechanism of regulating reproductive division of labor in ants; in Gadau J, Fewell JH (eds): Organization of Insect Societies: From Genome to Sociocomplexity. Cambridge, Harvard University Press, 220242.

Riffell JA, Lei H, Abrell L, Hildebrand JG (2013): Neural basis of a pollinator's buffet: olfactory specialization and learning in Manduca sexta. Science 339:200-204.

- Robinson GE (1992): Regulation of division of labor in insect docieties. Annu Rev Entomol 37 : 637-665.

Robinson GE, Heuser LM, Le Conte Y, Lenquette F, Hollingworth RM (1999): Neurochemicals aid bee nestmate recognition. Nature 399: 534-535.

Robson SK, Traniello JFA (1999): Key individuals and the organisation of labor in ants; in Detrain C, Pasteels JL (eds): Information Processing in Social Insects. Basel, Birkäuser, 239-259.

Robson SK, Traniello JFA (2002): Transient division of labor and behavioral specialization in the ant Formica schaufussi. Naturwissenschaften 89:128-131.

Roces F, Kleineidam C (2000): Humidity preference for fungus culturing by workers of the leaf-cutting ant Atta sexdens rubropilosa. Insectes Soc 47:348-350.

Roeder T (2005): Tyramine and octopamine: ruling behavior and metabolism. Annu Rev Entomol 50:447-477.

-Salomon M, Malka O, Vander Meer RK, Hefetz A (2012): The role of tyramine and octopamine in the regulation of reproduction in queenless worker honeybees. Naturwissenschaften 99: 123-131.

Sasaki K, Yamasaki K, Nagao T (2007): Neuroendocrine correlates of ovarian development and egg-laying behaviors in the primitively eusocial wasp (Polistes chinensis). J Insect Physiol 53:940-949.

Schluns EA, Wegener BJ, Robson SKA (2011): Genetic polyethism and nest building in the weaver ant Oecophylla smaragdina (FABRICIUS, 1775) (Hymenoptera: Formicidae). Myrmecol News 15:7-11.

Schultz TR, Brady SG (2008): Major evolutionary transitions in ant agriculture. Proc Natl Acad Sci USA 105:5435-5440.

-Schulz DJ, Barron AB, Robinson GE (2002): A role for octopamine in honey bee division of labor. Brain Behav Evol 60:350-359.

-Schulz DJ, Elekonich MM, Robinson GE (2003): Biogenic amines in the antennal lobes and the initiation and maintenance of foraging behavior in honey bees. J Neurobiol 54:406-416.

Schulz DJ, Robinson GE (2001): Octopamine influences division of labor in honey bee colonies. J Comp Physiol A Sens Neural Behav Physiol 187:53-61.

Seid MA, Castillo A, Wcislo WT (2011): The allometry of brain miniaturization in ants. Brain Behav Evol 77:5-13. 
-Seid MA, Goode K, Li C, Traniello JFA (2008): Age- and subcaste-related patterns of serotonergic immunoreactivity in the optic lobes of the ant Pheidole dentata. Dev Neurobiol 68: 1325-1333.

-Seid MA, Harris KM, Traniello JFA (2005): Agerelated changes in the number and structure of synapses in the lip region of the mushroom bodies in the ant Pheidole dentata. J Comp Neurol 488:269-277.

-Seid MA, Traniello JFA (2005): Age-related changes in biogenic amines in individual brains of the ant Pheidole dentata. Naturwissenschaften 92:198-201.

-Seid MA, Traniello JFA (2006): Age-related repertoire expansion and division of labor in Pheidole dentata (Hymenoptera: Formicidae): a new perspective on temporal polyethism and behavioral plasticity in ants. Behav Ecol Sociobiol 60:631-644.

-Shaw JC, Korzan WJ, Carpenter RE, Kuris AM, Lafferty KD, Summers CH, Overli O (2009): Parasite manipulation of brain monoamines in California killifish (Fundulus parvipinnis) by the trematode Euhaplorchis californiensis. Proc Biol Sci 276:1137-1146.

Skallova A, Kodym P, Frynta D, Flegr J (2006): The role of dopamine in Toxoplasma-induced behavioural alterations in mice: an ethological and ethopharmacological study. Parasitology 133:525-535.

-Smith AR, Muscedere ML, Seid MA, Traniello JFA, Hughes WO (2013): Biogenic amines differ between worker castes but not patrilines in the leafcutting ant Acromyrmex echinatior. J Comp Physiol A Neuroethol Sens Neural Behav Physiol, E-pub ahead of print.

- Smith CD, Zimin A, Holt C, Abouheif E, Benton R, Cash E, Croset V, Currie CR, Elhaik E, Elsik CG, Fave MJ, Fernandes V, Gadau J, Gibson JD, Graur D, Grubbs KJ, Hagen DE, Helmkampf M, Holley JA, Hu H, Viniegra ASI, Johnson BR, Johnson RM, Khila A, Kim JW, Laird J, Mathis KA, Moeller JA, MunozTorres MC, Murphy MC, Nakamura R, Nigam S, Overson RP, Placek JE, Rajakumar R, Reese JT, Robertson HM, Smith CR, Suarez AV, Suen G, Suhr EL, Tao S, Torres CW, van Wilgenburg E, Viljakainen L, Walden KKO, Wild AL, Yandell M, Yorke JA, Tsutsui ND (2011a): Draft genome of the globally widespread and invasive Argentine ant (Linepithema humile). Proc Natl Acad Sci USA 108: 5673-5678.

- Smith CR, Smith CD, Robertson HM, Helmkampf M, Zimin A, Yandell M, Holt C, Hu H, Abouheif E, Benton R, Cash E, Croset V, Currie CR, Elhaik E, Elsik CG, Fave MJ, Fernandes V, Gibson JD, Graur D, Gronenberg W, Grubbs KJ, Hagen DE, Viniegra ASI, Johnson BR, Johnson RM, Khila A, Kim JW, Mathis KA, Munoz-Torres MC, Murphy MC, Mustard JA, Nakamura R, Niehuis O, Nigam
S, Overson RP, Placek JE, Rajakumar R, Reese JT, Suen G, Tao S, Torres CW, Tsutsui ND, Viljakainen L, Wolschin F, Gadau J (2011b): Draft genome of the red harvester ant Pogonomyrmex barbatus. Proc Natl Acad Sci USA 108:5667-5672.

Snyder LE (1992): The genetics of social behavior in a polygynous ant. Naturwissenschaften 79 : 525-527.

-Spivak M, Masterman R, Ross R, Mesce KA (2003): Hygienic behavior in the honey bee (Apis mellifera L.) and the modulatory role of octopamine. J Neurobiol 55:341-354.

-Stevenson PA, Schildberger K (2013): Mechanisms of experience dependent control of aggression in crickets. Curr Opin Neurobiol 23: 318-323.

- Stieb SM, Hellwig A, Wehner R, Rössler W (2012): Visual experience affects both behavioral and neuronal aspects in the individual life history of the desert ant Cataglyphis fortis. Dev Neurobiol 72:729-742.

-Stieb SM, Kelber C, Wehner R, Rössler W (2011): Antennal lobe organization in desert ants of the genus Cataglyphis. Brain Behav Evol 77: 136-146.

-Stieb SM, Muenz TS, Wehner R, Rössler W (2010): Visual experience and age affect synaptic organization in the mushroom bodies of the desert ant Cataglyphis fortis. Dev Neurobiol 70:408-423.

-Stroeymeyt N, Guerrieri FJ, van Zweden JS, d'Ettorre P (2010): Rapid decision-making with side-specific perceptual discrimination in ants. PLoS One 5:12377.

Sturgis SJ, Gordon DM (2012): Nestmate recognition in ants (Hymenoptera: Formicidae): a review. Myrmecol News 16:101-110.

-Suen G, Teiling C, Li L, Holt C, Abouheif E, Bornberg-Bauer E, Bouffard P, Caldera EJ, Cash E, Cavanaugh A, Denas O, Elhaik E, Fave MJ, Gadau JR, Gibson JD, Graur D, Grubbs KJ, Hagen DE, Harkins TT, Helmkampf M, Hu H, Johnson BR, Kim J, Marsh SE, Moeller JA, Munoz-Torres MC, Murphy MC, Naughton MC, Nigam S, Overson R, Rajakumar R, Reese JT, Scott JJ, Smith CR, Tao S, Tsutsui ND, Viljakainen L, Wissler L, Yandell MD, Zimmer F, Taylor J, Slater SC, Clifton SW, Warren WC, Elsik CG, Smith CD, Weinstock GM, Gerardo NM, Currie CR (2011): The genome sequence of the leaf-cutter ant Atta cephalotes reveals insights into its obligate symbiotic lifestyle. PLoS Genet 7:e1002007.

Tedjakumala SR, Giurfa M (2013): Rules and mechanisms of punishment learning in honey bees: the aversive conditioning of the sting extension response. J Exp Biol 216:29852997.

Traniello JFA (2010): Pheidole: sociobiology of a highly diverse genus; in Breed MD, Moore J (eds): Encyclopedia of Animal Behavior. Oxford, Academic Press, 699-706.
Vander Meer RK, Preston CA, Hefetz A (2008): Queen regulates biogenic amine level and nestmate recognition in workers of the fire ant, Solenopsis invicta. Naturwissenschaften 95:1155-1158.

van der Woude E, Smid HM, Chittka L, Huigens ME (2013): Breaking Haller's rule: brain-body size isometry in a minute parasitic wasp. Brain Behav Evol 81:86.

Wada-Katsumata A, Yamaoka R, Aonuma H (2011): Social interactions influence dopamine and octopamine homeostasis in the brain of the ant Formica japonica. J Exp Biol 214:1707-1713.

-Waddington SJ, Hughes WOH (2010): Waste management in the leaf-cutting ant Acromyrmex echinatior: the role of worker size, age and plasticity. Behav Ecol Sociobiol 64:1219-1228.

-Waibel M, Floreano D, Magnenat S, Keller L (2006): Division of labour and colony efficiency in social insects: effects of interactions between genetic architecture, colony kin structure and rate of perturbations. Proc Biol Sci 273:1815-1823.

-Wehner R, Fukushi T, Isler K (2007): On being small: brain allometry in ants. Brain Behav Evol 69:220-228.

-Weisel-Eichler A, Haspel G, Libersat F (1999): Venom of a parasitoid wasp induces prolonged grooming in the cockroach. J Exp Biol 202:957-964.

Wilson EO (1980): Caste and division of labor in leaf-cutter ants (Hymenoptera, Formicidae, Atta). 1. The overall pattern in Atta Sexdens. Behav Ecol Sociobiol 7:143-156.

Wilson EO (2003): Pheidole in the New World: A Dominant, Hyperdiverse Ant Genus. Cambridge, Harvard University Press.

Wnuk A, Wiater M, Godzinska EJ (2010): Effect of past and present behavioural specialization on brain levels of biogenic amines in workers of the red wood ant Formica polyctena. Physiol Entomol 36:54-61.

Wurm Y, Wang J, Riba-Grognuz O, Corona M, Nygaard S, Hunt BG, Ingram KK, Falquet L, Nipitwattanaphon M, Gotzek D, Dijkstra MB, Oettler J, Comtesse F, Shih CJ, Wu WJ, Yang CC, Thomas J, Beaudoing E, Pradervand S, Flegel V, Cook ED, Fabbretti R, Stockinger H, Long L, Farmerie WG, Oakey J, Boomsma JJ, Pamilo P, Yi SV, Heinze J, Goodisman MAD, Farinelli L, Harshman K, Hulo N, Cerutti L, Xenarios I, Shoemaker D, Keller L (2011): The genome of the fire ant Solenopsis invicta. Proc Natl Acad Sci USA 108:5679-5684.

Zhou C, Rao Y, Rao Y (2008): A subset of octopaminergic neurons are important for Drosophila aggression. Nat Neurosci 11:1059-1067.

-Zube C, Kleineidam CJ, Kirschner S, Neef J, Rössler W (2008): Organization of the olfactory pathway and odor processing in the antennal lobe of the ant Camponotus floridanus. J Comp Neurol 506:425-441. 